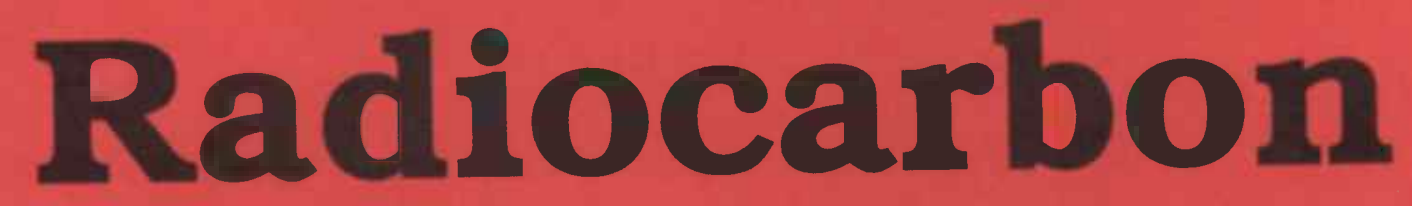

An International Journal of Cosmogenic Isotope Research
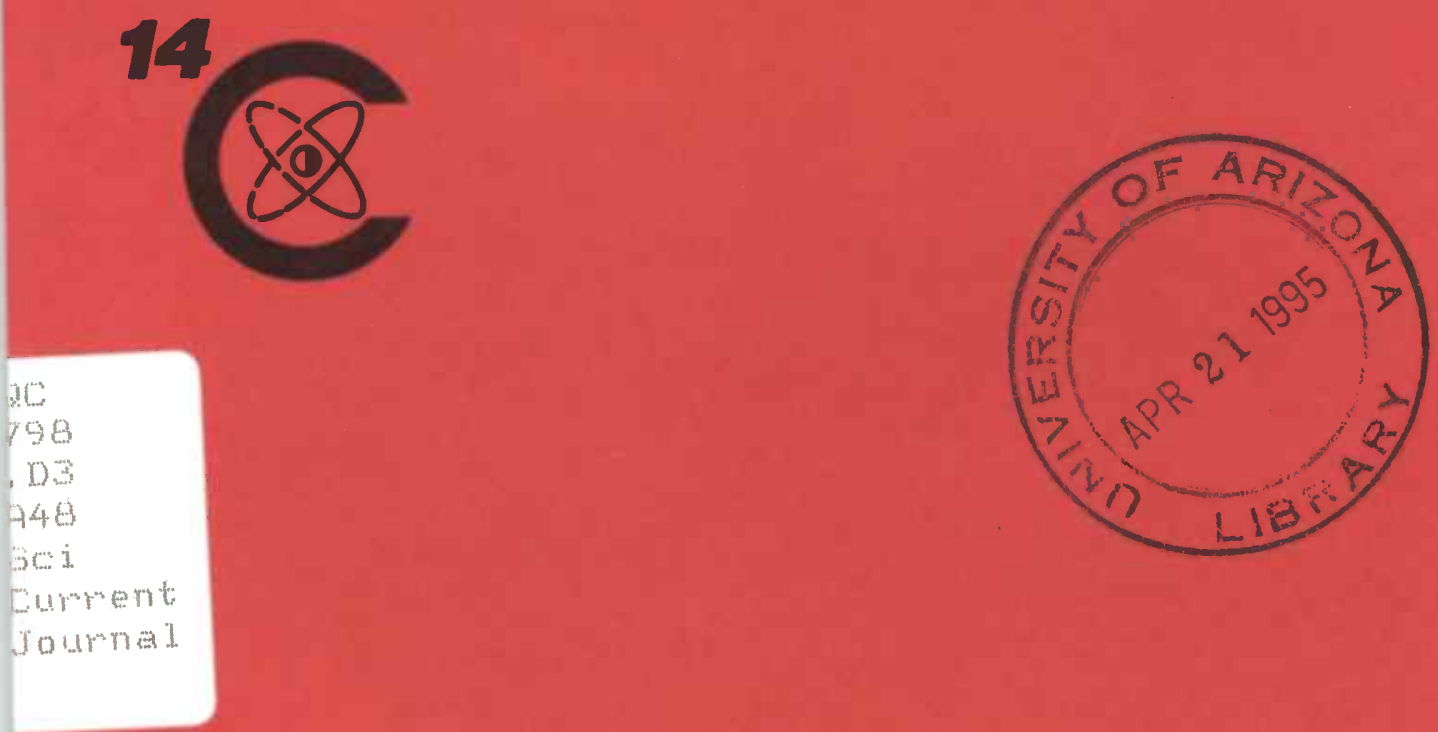

\title{
Editor
}

AUSTIN LONG

\section{Consulting Editor}

A. J. T. JULL

Managing Editor

RENEE S. KRA

Assistant Editors

DAVID R. SEWELL

KIMBERLEY L. TANNER

Department of Geosciences

The University of Arizona

4717 East Ft. Lowell Road

Tucson, Arizona 85712 USA 


\title{
RADIOCARBON
}

An International Journal of Cosmogenic Isotope Research

\author{
Editor: AusTIN LONG \\ Consulting Editor: A. J. T. JULL \\ Managing Editor: RENEE S. KRA \\ Assistant Editors: DAVID R. SEWELL, KIMBERLEY L. TANNER \\ Published by \\ Department of Geosciences \\ The University of Arizona
}

Published three times a year at The University of Arizona, Tucson, AZ 85712 USA. (O) 1994 by the Department of Geosciences, The University of Arizona.

Subscription rate (1995): $\$ 115.00$ (for institutions), $\$ 85.00$ (for individuals), $\$ 42.50$ (for students with proper identification). Foreign postage is extra. A complete price list, including Proceedings of International Conferences, special publications and 1995 subscription categories, appears in the-back of this issue. Back issues may be obtained by contacting RADIOCARBON.

All correspondence and manuscripts should be addressed to the Managing Editor, RADIOCARBON, Department of Geosciences, The University of Arizona, 4717 East Ft. Lowell Road, Tucson, AZ 85712 USA. Tel: (520) 881-0857; Fax: (520) 881-0554. (N.B.: new telephōné area code!) Please note our e-mail addresses:

\section{BITNET: C14@ARIZVMS \\ INTERNET: c14@packrat:aml.arizona.edu \\ or rkra@packrat.aml.arizona.edu}

Offprints. The minimum offprint order for each article will be 100 copies without covers. No offprints will be furnished free of charge unless páge charges are paid (see below). Covers åre also available.

Page charges. For 1995, each institution sponsoring research reported in a technical paper or a date list will be asked to pay a charge of $\$ 50.00$ per printed page. This represents a $\$ 30$ reduction in price from 1994 . Institutions or authors paying such charges will be entitled to 100 free offprints without covers. No charges will be made if the author indicates that the author's institution is unable to pay, and payment of page charges for an article will, in no case, be a condition for its acceptance.

Missing issues will be replaced without charge only if claim is made within three months (six months for India, New Zealand and Australia) after the publication date. Claims for-missing issues will not be honored if non-delivery results from failure by the subscriber to notify the Journal of än address change.

Illustrations should include explanation of symbols used. Copy that cannot be reproduced cannot be accepted. Whenever possible, reduce figures for direct publication. Line drąings should be in black India ink on white drawing board, tracing cloth, or coordinate paper printed in blue and should be accompanied by clear ozalids or reduced photographs for use by the reviewers. Photographs should be positive prints. Figures (photographs and line drawings) should be numbered consecutively through each article, using Arabic numerals. Tables may be accepted as camera-ready copy.

Citations. A number of radiocarbon dates appear in publications without laboratory çitation or reference to published date lists. We ask authors of research articles and date lists to include proper citation (laboratory number and date-list citation) in all publications in which radiocarbon dates appear.

Radiocarbon Measurements: Comprehensive Index, 1950-1965. This iñdex, covers all published ${ }^{14} \mathrm{C}$ measurements through Volume 7 of RADIOCARBON, and incorporates revisions made by all laborafớries. It is available at $\$ 25.00$ per copy.

List of laboratories. Our comprehensive list of laboratories is available upon request. We are expanding the list to include additional laboratories and scientific agencie's with whom we have established contacts. The editors welcome information on these or other scientific organizations. We ask all laboratory directors to provide their laboratory code designation, as well as current telephone and fax numbers, and e-mail addresses. Chariges in names or addresses, additions or deletions should be reported to the Managing Editor. Conventional and AMS laboratories are now arranged in alphabetical order by country and we include laboratories listed by code designation. 


\section{CONTENTS}

FROM THE EDITORS - To Our Friends (Continued)

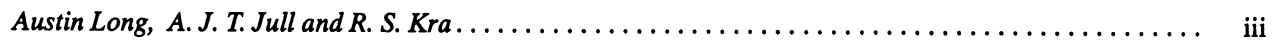

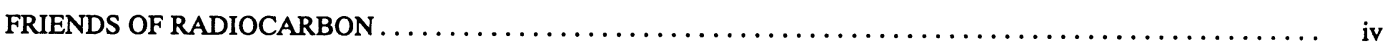

OBITUARY

Ulrich Siegenthaler

Heinz H. Loosli. . .

ARTICLES

On the ${ }^{14} \mathrm{C}$ and ${ }^{39} \mathrm{Ar}$ Distribution in the Central Arctic Ocean: Implications for Deep Water Formation Peter Schlosser, Bernd Kromer, Gote Östlund, Brenda Ekwurzel, Gerhard Bönisch, H. H. Loosli and Roland Purtschert.

Human Settlements and the Last Deglaciation in the French Alps

Jacques Evin, Pierre Bintz and Guy Monjuvent .

Radiocarbon Dating of the Stone and Bronze Age Sites in Primorye (Russian Far East) Yaroslav V. Kuzmin, Lyobov A. Orlova, Leopold D. Sulerzhitsky and A. J. T. Jull . . . . . . . . . . . . . . . . 359

Prehistoric Colonization of Northeastern Siberia and Migration to America: Radiocarbon Evidence Yaroslav V. Kuzmin

Radiocarbon Dating Sites of Northwest Russia and Latvia

G. I. Zaitseva and S. G. Popov.

Dating the Prehistoric Site Nahal Issaron in the Southern Negev, Israel Israel Carmi, Dror Segal, A. N. Goring-Morris and Avi Gopher

Comparison of Manual and Automated Pretreatment Methods for AMS Radiocarbon Dating of Plant Fossils Lee-Ann Bradley and Thomas W. Stafford, Jr.

Pollen Concentrate Preparation from Highly Organic Holocene Peat and Lake Deposits for AMS Dating Ffiona Richardson and Valerie A. Hall.

RADIOCARBON UPDATES

LABORATORIES 417

AUTHOR INDEX 441

SUBJECT INDEX 


\section{ASSOCIATE EDITORS}

For Accelerator Physics

DAVID ELMORE

ROBERT E. M. HEDGES

West Lafayette, Indiana, USA

D. ERLE NELSON

Oxford, England

Burnaby, British Columbia, Canada

For Archaeology

ANDREW M. T. MOORE

MICHAEL B. SCHIFFER

New Haven, Connecticut, USA

Tucson, Arizona, USA

For Atmospheric Sciences

GEORGE A. DAWSON

KUNIHIKO KIGOSHI

DAVID C. LOWE

For Geochemistry

PAVEL POVINEC

MINZE STUIVER

For Geophysics

\section{G. E. KOCHAROV \\ WILLEM G. MOOK}

For Ice Studies

HAROLD W. BORNS, JR.

For Oceanography

EDOUARD BARD

ELLEN R. M. DRUFFEL

For Paleobotany

CALVIN J. HEUSSER
Auckland, New Zealand

Tucson, Arizona, USA

Tokyo, Japan

Lower Hutt, New Zealand

Bratislava, Slovakia

Monaco

Seattle, Washington, USA

St. Petersburg, Russia

Texel, The Netherlands

Orono, Maine, USA

Gif-sur-Yvette, France

Marseille, France

Palisades, New York, USA

Irvine, California, USA

Tuxedo, New York, USA 